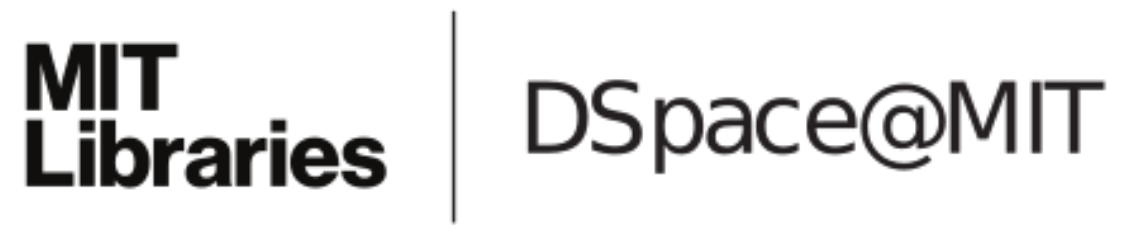

\author{
MIT Open Access Articles
}

Precipitation, Recycling, and Land Memory: An Integrated Analysis

The MIT Faculty has made this article openly available. Please share how this access benefits you. Your story matters.

Citation: Dirmeyer, Paul A, C. Adam Schlosser, and Kaye L Brubaker. "Precipitation, Recycling, and Land Memory: An Integrated Analysis." Journal of Hydrometeorology (2009): 278-288. () 2008 American Meteorological Society

As Published: http://dx.doi.org/10.1175/2008JHM1016.1

Publisher: American Meteorological Society

Persistent URL: http://hdl.handle.net/1721.1/52326

Version: Final published version: final published article, as it appeared in a journal, conference proceedings, or other formally published context

Terms of Use: Article is made available in accordance with the publisher's policy and may be subject to US copyright law. Please refer to the publisher's site for terms of use. 


\title{
Precipitation, Recycling, and Land Memory: An Integrated Analysis
}

\author{
PAUl A. DiRMEYER \\ Center for Ocean-Land-Atmosphere Studies, Calverton, Maryland
}

C. ADAM SCHLOSSER

MIT Joint Program on the Science and Policy of Global Change, Cambridge, Massachusetts

KAYE L. BRUBAKER

Department of Civil and Environmental Engineering, University of Maryland, College Park, College Park, Maryland

(Manuscript received 11 February 2008, in final form 1 July 2008)

\begin{abstract}
A synthesis of several approaches to quantifying land-atmosphere interactions is presented. These approaches use data from observations or atmospheric reanalyses applied to atmospheric tracer models and stand-alone land surface schemes. None of these approaches relies on the results of general circulation model simulations. A high degree of correlation is found among these independent approaches, and constructed here is a composite assessment of global land-atmosphere feedback strength as a function of season. The composite combines the characteristics of persistence of soil moisture anomalies, strong soil moisture regulation of evaporation rates, and reinforcement of water cycle anomalies through recycling. The regions and seasons that have a strong composite signal predominate in both summer and winter monsoon regions in the period after the rainy season wanes. However, there are exceptions to this pattern, most notably over the Great Plains of North America and the Pampas/Pantanal of South America, where there are signs of land-atmosphere feedback throughout most of the year. Soil moisture memory in many of these regions is long enough to suggest that real-time monitoring and accurate initialization of the land surface in forecast models could lead to improvements in medium-range weather to subseasonal climate forecasts.
\end{abstract}

\section{Introduction}

The atmospheric branch of the hydrologic cycle is a crucial component of weather and climate, and it is highly consequential for many aspects of society and health of life on earth (Hornberger et al. 2001). Much of the motivation for weather and climate prediction stems from the importance of water (namely, precipitation). However, the nonlinear characteristics of fluid flow on a sphere, combined with the complicating physical processes brought about by thermodynamics, phase changes of water, surface heat fluxes from below, solar heat flux from above, and so forth, mean that simple

Corresponding author address: Paul A. Dirmeyer, Center for Ocean-Land-Atmosphere Studies (COLA), 4041 Powder Mill Road, Suite 302, Calverton, MD 20705.

E-mail: dirmeyer@cola.iges.org extrapolation cannot get one very far in weather prediction. Numerical models have been developed that explicitly represent many of these processes and parameterize others, giving a better simulation of the nonlinear atmospheric evolution and a tool for prediction. However, nonlinearity dictates that skill drops with increasing time from the initial condition, so there remains an upper temporal bound to deterministic prediction of the atmosphere (Lorenz 1963). Conventionally, this limit is taken to be around 2 weeks (Lorenz 1969).

The ocean influences the atmospheric circulation, heat, and moisture content through its surface temperature. The ocean has an enormous heat capacity and relatively slow circulation. Thus, anomalies in the ocean that might lead to anomalies in climate tend to change slowly. This provides an extended element of memory, which aids prediction on monthly to annual time scales. 
In particular, it is now accepted that variability in the tropical oceans, particularly in the Pacific, is crucial to climate variations around the globe [World Climate Research Programme 1995 (WCRP)].

Less well understood or applied toward forecasting is the memory inherent in the land surface state. The land surface does not have the large heat capacity and thermal inertia of the ocean. Nevertheless, it does change slowly-compared to the atmosphere-in terms of its moisture storage, vegetation, and snow cover. Variations in these quantities affect the atmospheric state and circulation through the transfer of heat, moisture, and momentum between the atmosphere and the surface. Soil moisture, and the memory of its anomalies, has been found to be an important element of weekly to seasonal variability (e.g., Beljaars et al. 1996; Fennessy and Shukla 1999; Koster and Suarez 1999; Dirmeyer 2000; Douville 2002; Schlosser and Milly 2002), potentially manifesting its influence on the atmosphere through variations in evapotranspiration. Thus, the water cycle is the key pathway for improving climate prediction via land surface memory. In Koster and Suarez (2001), an analytic description is provided, whereby the controls of memory are identified as the result of 1) the seasonal aspects of soil moisture variations, 2) the "inherent" controls from the interplay of evaporation and runoff with soil moisture, and-more importantly for our study-3) the associated variations and feedbacks between the land and the atmosphere (i.e., precipitation, temperature, radiation). In terms of climate and weather prediction, more accurate observations of soil moisture could translate into more reliable forecasts of soil moisture directly from the first two controls of memory. More importantly, however, it is in the identification and depiction of regions with coupled associations between soil moisture and the atmosphere that will aid in the skill of weather forecasts and climate predictions.

We therefore hypothesize that not only are interactions between the land and atmosphere a considerable source of land surface memory but that this memory poses an element of coupled land-atmosphere predictability in the climate system that can advance water cycle prediction. In this paper, we bring together disparate methods and datasets to investigate evidence of land-atmosphere feedbacks. In so doing, we wish to avoid the possibility of a particular result being the artifact of a single model or dataset. If there are indeed climatic feedbacks and interactions between land and atmosphere, they should be evident in each of the branches of the hydrologic cycle and present in various sources of data. Any positive results would therefore be reinforced by having multiple sources of evidence. Thus, we attempt to synthesize evidence from several data sources and calculations, each focusing on a different element of the water cycle. Unlike previous studies, this study does not use results from weather or climate model forecasts. It builds on observational data and model-based products or calculations that are highly constrained by observations.

The next section describes the datasets used and some of the further analyses performed in the course of this work. Sections 3-5 each examine a specific connection in the global water cycle that we believe is key to identifying evidence of land-atmosphere feedbacks. Section 6 presents the synthesis of these connections, and conclusions are given in section 7 .

\section{Data}

\section{a. Land surface states and fluxes}

The second Global Soil Wetness Project (GSWP-2; Dirmeyer et al. 2006a) produced a 10-yr daily global gridded ( $1^{\circ}$ resolution) dataset of land surface state variables and fluxes. These data were produced by driving over a dozen different land surface models with identical meteorological forcings. The forcings were taken from National Centers for Environmental Prediction-Department of Energy (NCEP-DOE) global reanalysis data (Kanamitsu et al. 2002) after correcting identifiable errors and biases with a number of specific global observational data. The GSWP dataset covers the period 1986-95. The results from the land surface models were checked for quality, consistency, and conservation of mass and energy, corrected when problems were detected, and then combined to produce a multimodel land surface analysis. This analysis has been validated and shown to be superior to any individual model in terms of its representation of soil moisture variations (Guo and Dirmeyer 2006).

Version 2 of the Global Offline Land surface Dataset (GOLD-2) is produced in a very similar manner to GSWP-2. However, only one land surface model was used (SSiB; Xue et al. 1996, 1991; Dirmeyer and Zeng 1999). The period of coverage spans the late 1950s into 2003. This dataset uses the 40-yr European Centre for Medium-Range Weather Forecasts (ECMWF) reanalysis (ERA-40) as the basis of its forcing data (Simmons and Gibson 2000) with corrections applied only to precipitation (Rudolf et al. 1994). Finally, GOLD-2 is on a coarser-resolution spatial grid, matching the T-62 Gaussian grid $\left(1.875^{\circ}\right.$ longitude by approximately $1.9^{\circ}$ latitude) of the reanalysis grid of Kanamitsu et al. (2002). 
As implied above, these two renditions of the global land surface state have different strengths. The GSWP-2 multimodel analysis has a higher spatial resolution and a demonstrably better simulation of soil moisture, but it is limited to only ten years. This short time span limits sample sizes in statistical analyses and makes it difficult to find statistically significant relationships with this dataset. On the other hand, the GOLD-2 data has a much longer span (in fact, due to limitations in the data we have on recycling described below, we are limited to a 24-yr period for our calculations). However, the quality of the GOLD-2 analysis is slightly inferior to GSWP-2 in the representation of soil moisture variability when compared to in situ observations (Guo et al. 2007). This is likely due to two factors. First, the inherent biases and shortcomings of a single model are compensated for by a multimodel approach. Second, correction of the reanalysis is restricted to precipitation for GOLD-2. This is arguably the most important field to correct for a water cycle study, but errors in other fields such as radiation or surface temperature are not insignificant (Guo et al. 2006).

\section{b. Soil moisture memory}

Both GSWP-2 and GOLD-2 daily soil moisture data are used to estimate the soil moisture memory at each location, stratified by season [December-February (DJF), March-May (MAM), June-August (JJA), and September-November (SON)]. Memory, measured in days, is defined as the average time required for the lagged autocorrelation of soil moisture to drop below the $99 \%$ confidence level (C. A. Schlosser and P. A. Dirmeyer 2007, unpublished manuscript). Lags are calculated backward in time, so a 90-day memory during spring, for instance, indicates memory of winter anomalies into spring and not persistence of spring conditions into summer. For both the GSWP-2 and GOLD-2 estimates, the root-zone soil moisture is used. The patterns, shown in Fig. 1, are similar between the two products outside of boreal winter, but more importantly they vary similarly in time. Only $16 \%$ of the land area does not have strong positive correlation over the 10-yr period of overlap, providing confidence that they can be substituted for one another when necessary. The main differences are in the magnitudes-GOLD-2 estimates tend to have less range over the globe, generally having memories neither as short nor as long as those indicated from GSWP-2. GOLD-2 also tends to have a region of longer memory over the eastern United States that is only evident in the GSWP-2 estimates during summer, and a somewhat different annual cycle over high-latitude permafrost areas where the simple GOLD-2 snow and frozen soil parameterizations cast some doubt on the results.

\section{c. Recycling}

Estimates of atmospheric water recycling ratios are available on the same grid as the GOLD-2 data spanning 1979-2003 (Dirmeyer and Brubaker 2007). These estimates are independent of GOLD-2 in terms of input data. The recycling ratio is defined as the fraction of precipitation falling over a specified area that originated as surface evapotranspiration most recently from the same area. Recycling is estimated by performing back-trajectory calculations from precipitation events occurring over each land grid box (Dirmeyer and Brubaker 1999; Brubaker et al. 2001; Sudradjat et al. 2003). Accounting is done in terms of water mass, rather than $E-P$, where $E$ is evaporation and $P$ is precipitation (Stohl and James 2005), and unlike pure passive-tracer approaches (e.g., Brimelow and Reuter 2005), surface fluxes are included to pinpoint source regions. Observational precipitation products and the reanalysis of Kanamitsu et al. (2002) are used to establish the time and place of each precipitation event. Data for this reanalysis are only available from 1979 onward. Calculations based on winds, humidity, temperature, and evapotranspiration from the same reanalysis determine from where the moisture came to supply the precipitation. The evaporation source for individual precipitation events can be estimated this way (Reale et al. 2001; Turato et al. 2004). Accumulated in time, the result is a "fetch" of surface sources for the precipitation over each terrestrial grid box summed for each month. The fraction of that fetch within the target grid box is the recycled portion. These results can be aggregated to larger areas (e.g., major river basins or countries) or scaled to a common reference surface area.

The precipitation used in recycling calculations and the land surface model integrations is produced by combining gridded observed and reanalysis precipitation estimates. This is done because no existing dataset is ideal. Observed datasets are the closest to "ground truth" but are uneven in quality and coverage. The most accurate products are available on time intervals that are too long for our purposes (monthly for global products). Model precipitation, such as that from reanalyses, has complete coverage and is available at subdiurnal time steps. Although this precipitation typically mirrors well the time series of observed precipitation because atmospheric state variables are constrained by data assimilation, there are typically strong time-mean and diurnal biases. Some satellite products are now 


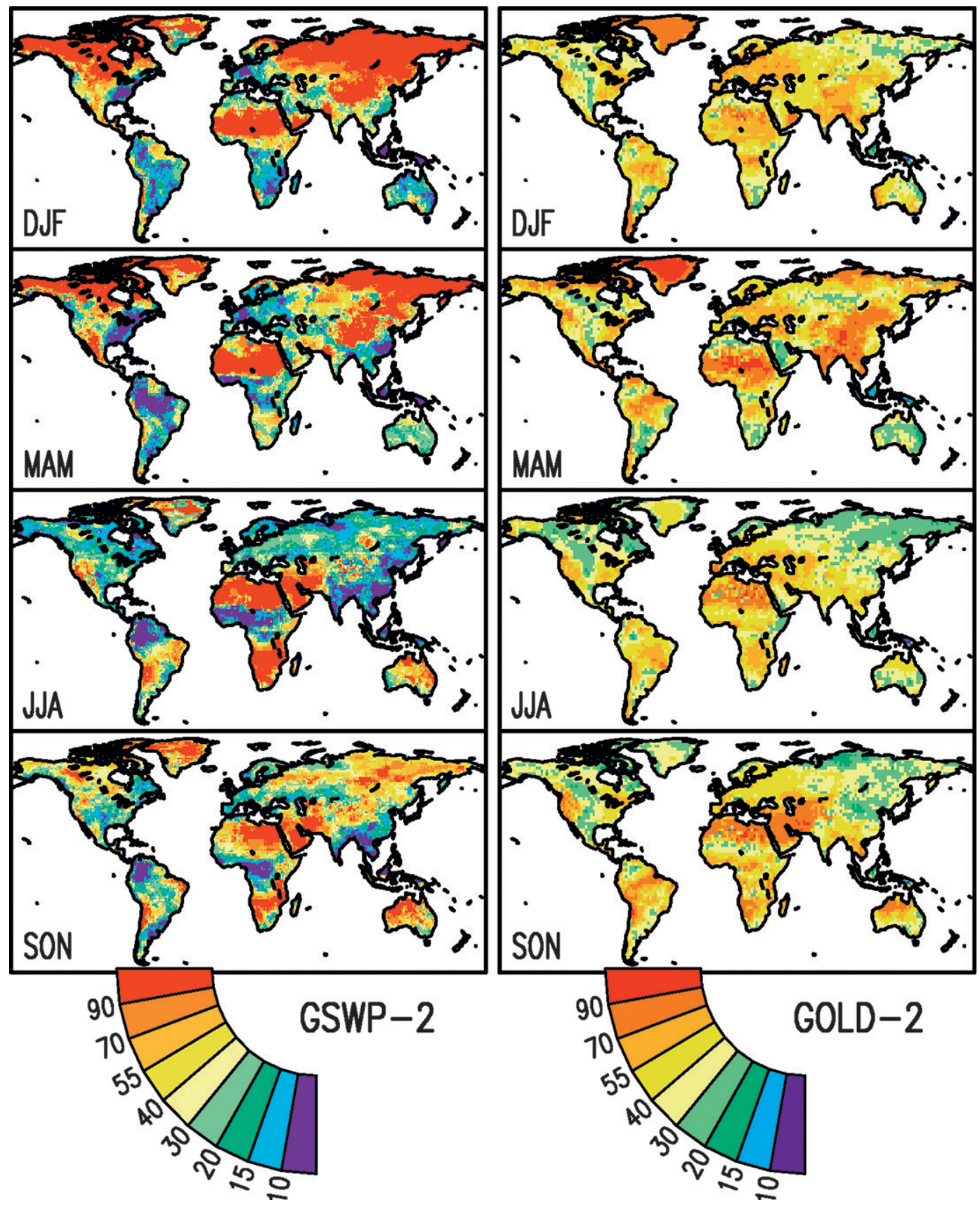

FIG. 1. Soil moisture memory time scale (days) for (left) GSWP-2 and (right) GOLD-2. See text for details.

available that have an observational basis, near-global coverage, and subdiurnal temporal resolution. However, these products are rather recent and only cover a few years. Through a process of scaling, we have combined these products to preserve observed monthly means and satellite observed diurnal cycles using reanalyses to impart realistic synoptic variability to the precipitation time series (Dirmeyer and Brubaker 2007). For GSWP-2 and GOLD-2, there has been no scaling to match satellite diurnal cycles (e.g., Zhao and Dirmeyer 2003).

\section{d. Climatologies}

Figure 2 shows the mean annual cycle for GSWP-2 total column soil wetness (left column; $0=$ wilting point, 1 = saturation) and recycling ratio scaled to a common area of $10^{5} \mathrm{~km}^{2}$ (right column). At nearly any geographical location, one can see a clear and pro- 


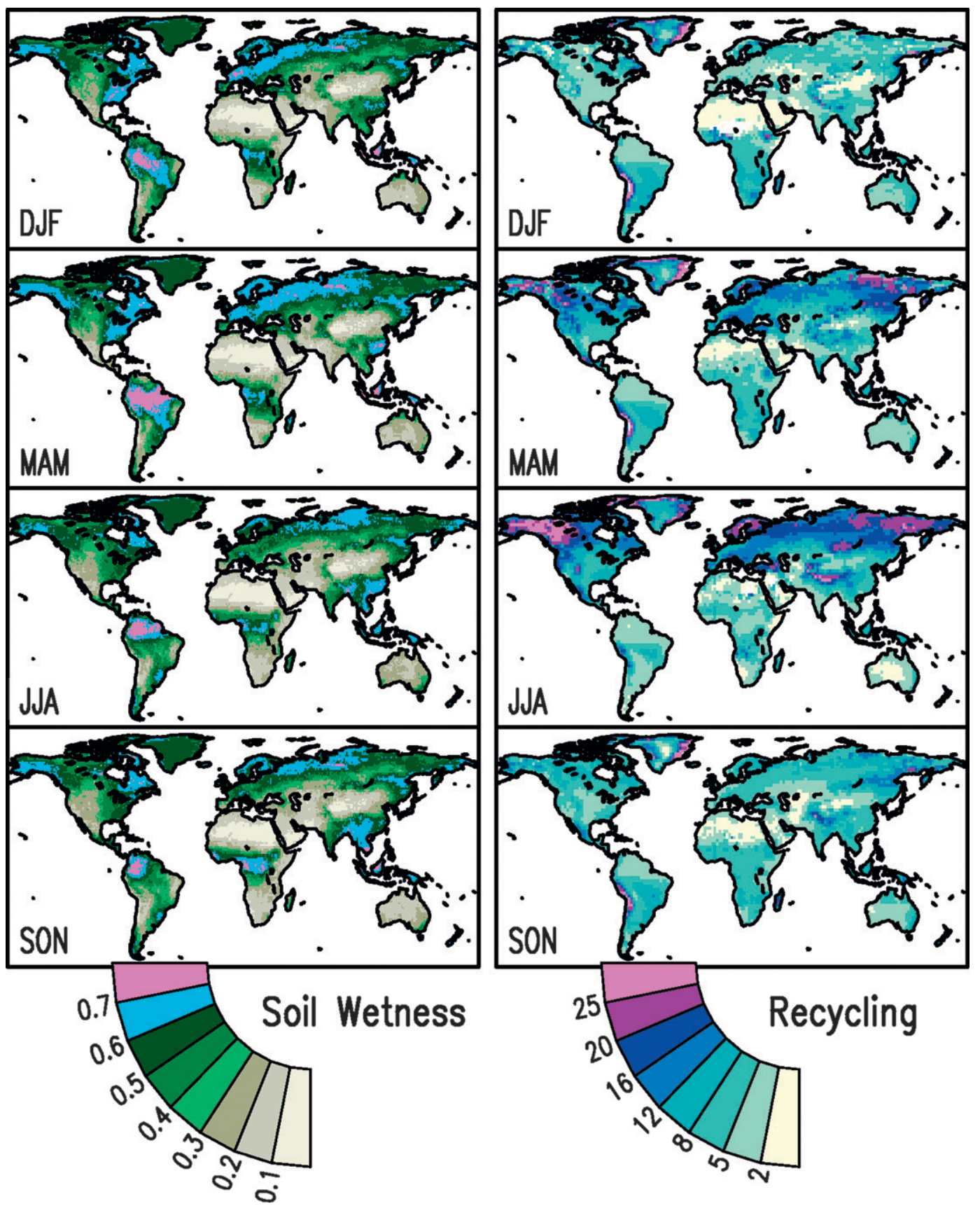

FIG. 2. Total soil wetness from (left) GSWP-2 ( 0 = wilting point, $1=$ saturation $)$ and (right $)$ recycling ratio (percent). See text for details.

nounced annual cycle in these terms. Soil moisture largely follows precipitation (more accurately precipitation minus evaporation) or, at high latitudes, the snowmelt cycle. The annual cycle of memory (Fig. 1) also follows precipitation and temperature: longer memories in wetter and/or colder times of year. Long memories predominate where snow cover exists and in arid regions. Recycling is strongly tied to evaporation rates and moisture transport. Like memory, recycling has the largest annual cycles at high latitudes where winters are windy with little evaporation, and summers have high evaporation with reduced moisture advection.

Given the background of the mean annual cycles shown in Figs. 1, 2, we would like to know where and how the variations in these diagnostic measures are re- 
lated. Is there evidence to link anomalies or interannual variations between these terms? If so, through what physical means are they linked? The form of the linked relationships can reveal how land-atmosphere interactions operate within the global water cycle.

\section{Soil moisture-evaporation connection}

Dirmeyer (2006) described a feedback loop in the water cycle between land and atmosphere. The feedback loop can be visualized as a diminishing cascade where precipitation very strongly determines soil moisture; soil moisture exerts a moderate level of control on evapotranspiration (ET); and the influence of ET back on precipitation is tenuous. The strong correlation between precipitation and soil moisture is well established and will not be revisited here but to say that we find $99 \%$ significance in correlations globally, except over portions of the Eastern Hemisphere deserts. However, the character of the relationship between soil moisture and ET can set the direction of the feedback.

Figure 3 shows the correlation between daily soil moisture and total ET in the GSWP-2 multimodel analysis. The mean annual cycle, smoothed by a centered 31-day running average, has been removed from both variables before the correlations are calculated. The values for each season represent the average temporal correlation for all days in the given season across all ten years.

Many arid and semiarid regions maintain year-round positive correlations. Humid regions can maintain negative correlations in all seasons. Many areas have a pronounced annual cycle in the connection between soil moisture and ET. Regions experiencing snow cover typically have no correlation between soil moisture and ET, probably because snow cover prevents soil moisture from having a direct physical connection to ET.

A positive correlation between soil moisture and ET is consistent with the mechanism proposed for positive feedback in the water cycle. It suggests that soil moisture controls evaporation. This is likely to occur where moisture is more limited than either the energy required to evaporate water from the surface (generally net radiation) or the advective/convective energy needed to maintain a water vapor gradient. When soil moisture is available, ET increases. On the other hand, negative correlations suggest that it is ET that controls soil moisture. When ET increases, it draws down soil moisture; when ET decreases, soil moisture is preserved. This situation occurs when the limits on ET are not caused by a lack of moisture. The limits could be caused by a lack of available energy (typical in high latitudes) or conditions in which the supply by precipi-

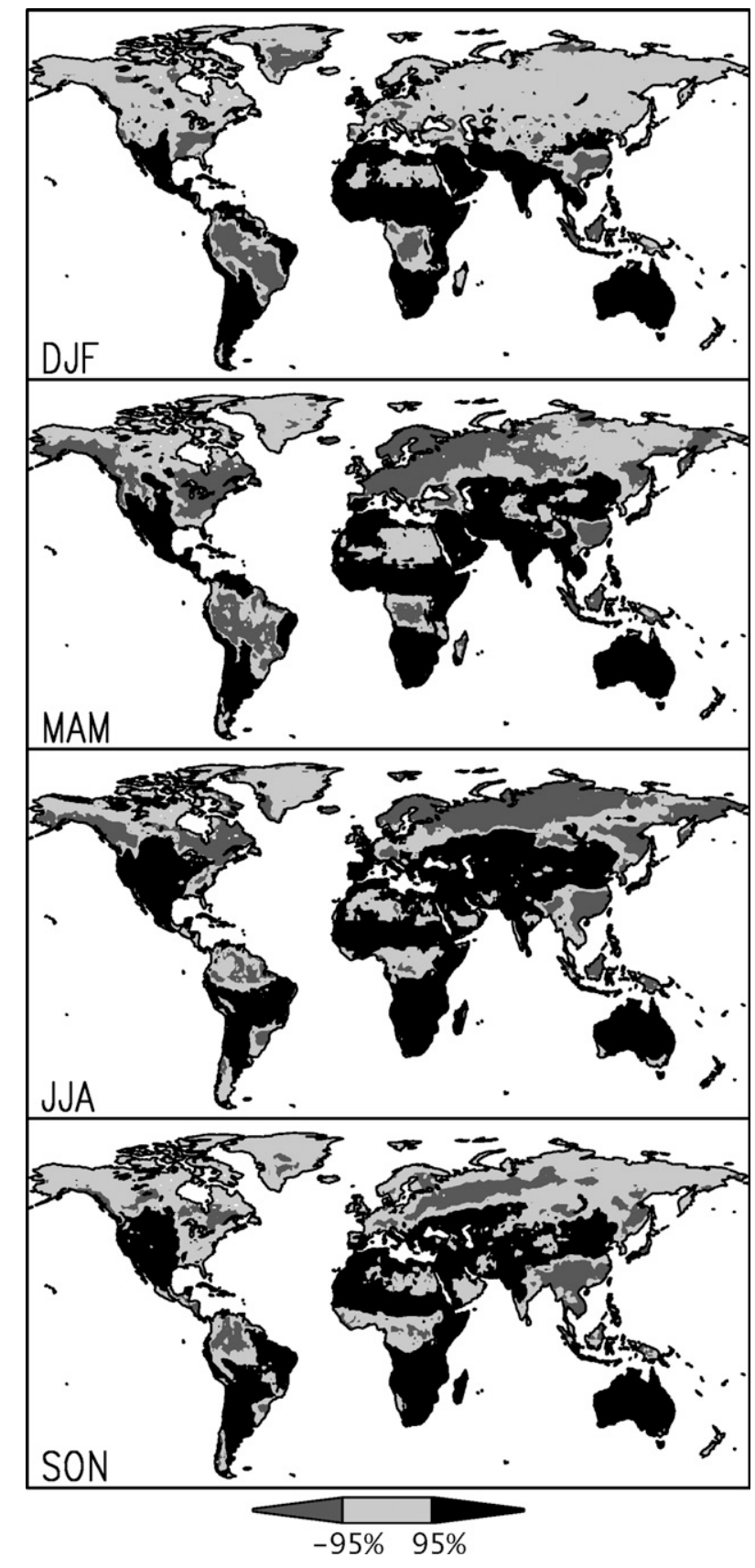

FIG. 3. Regions of significant correlation between GSWP-2 multimodel analysis estimates of daily evapotranspiration and layer-2 soil moisture.

tation is a stronger driver than the demand by ET (cloudy, stormy conditions like in the deep tropics). This condition interrupts the feedback loop described at the beginning of this section by reversing the direction of the flow of information. Thus, a positive correlation between soil moisture and ET is a necessary but not sufficient condition for land-atmosphere feedback. 
We would not expect to find the land surface state affecting climate outside of the darkest areas of Fig. 3.

It should be noted that Fig. 3 represents the climatology of the connection between soil moisture and ET on a 1-day basis. Details could vary from year to year, and regions on the margins between dark and light shading could be important contributors to landatmosphere feedback in some years but not in others. We have performed the same calculation for $24 \mathrm{yr}$ of daily data from GOLD-2, and the patterns and magnitudes are similar-positive correlations extend more prominently into high latitudes, but south of $55^{\circ} \mathrm{N}$ it is very similar to Fig. 3. Furthermore, calculations performed on monthly GOLD-2 data also show similar results with a few regional differences. Monthly correlations appear to be slightly higher (more significant) than daily, with the exception of monsoon regions during their respective dry seasons, where the monthly correlations are generally lower. Otherwise, the large-scale patterns and magnitudes are quite similar, suggesting that the low-frequency signals dominate the correlations.

\section{Evaporation-memory connection}

Figure 4 shows the correlations between monthly estimates of total ET and soil moisture memory from the 24-yr GOLD-2 data. This component tends to highlight those places that are transitioning between wet and dry conditions, passing through a middle sensitive zone between humid and arid where evaporation has the greatest sensitivity to small changes in soil moisture (Dirmeyer et al. 2000).

Positive correlations are constrained to areas that are coming out of their wettest season. For example, high correlations are found during the equinox seasons where the intertropical convergence zone (ITCZ) has moved equatorward-SON for the Northern Hemisphere (Sahel, Mexico) and MAM for the Southern (South Africa, South America). In continental climates (central United States, Eurasia), high correlations occur during spring, corresponding to the transition between typically wet winters and dry summers.

The mechanism can be understood by realizing that ET is high when the land surface is wet; this elevated rate of ET persists into the start of the dry season, establishing the pattern for the wet-to-dry transition phase of the mean annual cycle. A negative anomaly at this time of year is indicative of a weak monsoon or wet season, and memory is lost more quickly than in an average or wet year. The faster dry-down results in concomitant negative anomalies in ET and soil moisture memory. An extended wet season generates posi-

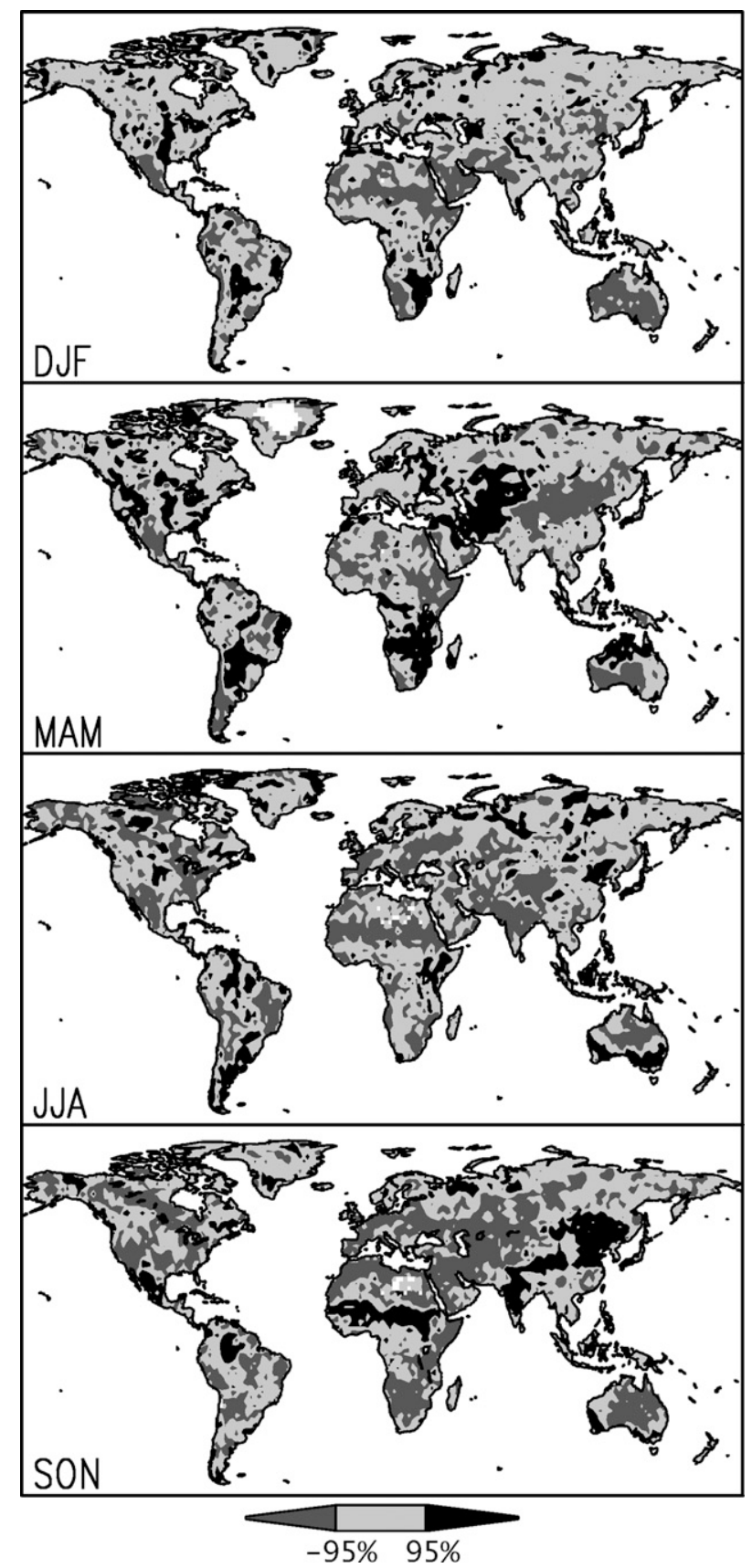

FIG. 4. Same as Fig. 3, but for GOLD-2 monthly evapotranspiration and soil moisture memory.

tive anomalies in each as soil wetness remains near maximum values.

Spatially, negative correlations are more prevalent than positive correlations. Temporally, negative values tend to occur when areas are deep into their driest seasons. Dry-down with no rain results in an asymptotic drop in soil moisture and ET with time, and the initial state (soil moisture at the start of the dry season) sets 
the sign of the anomaly that persists until precipitation returns. This mechanism explains the areas of high memory in arid zones and semiarid zones during the dry season seen in Fig. 1. If this dry-down is interrupted by rainfall, soil moisture and ET are driven up, and memory of the persistent anomaly (especially if negative) is lost. Under these conditions, rainfall is essentially noise.

\section{Soil moisture-recycling connection}

The correlation of monthly GOLD-2 soil moisture to monthly recycling ratios is shown by season in Fig. 5 . Negative correlations are straightforward to understand. Because soil moisture goes up when precipitation increases, an anticorrelation with recycling ratio suggests that wet anomalies are supplied mainly by moisture advected from elsewhere. Typically, the external source of moisture is oceanic, but this is not always the case. One exception is evident in the top of Fig. 5. Negative anomalies over much of the La Plata River basin correspond to an increase of moisture advected around the South Atlantic subtropical ridge from the Amazon basin to the north.

Positive correlations, on the other hand, suggest that soil moisture anomalies reinforce local precipitation anomalies through positive feedback. Figure 5 shows that regions of positive correlations tend toward semiarid regions but can extend into more humid areas of the tropics and extratropics. In these regions, recycling ratio is more strongly tied to local ET, and thus to soil moisture, than to advection of moisture from outside the region.

The correlations between recycling ratio and ET or precipitation are quite similar to Fig. 5, but are not shown.

\section{Synthesis}

Figure 6 is a composite of the results shown in the previous sections. In this figure, the soil moisture memory time scale from the left column of Fig. 1 is redisplayed, but with most of the land areas masked out. Only those regions that show positive correlations in each of the three Figs. 3-5 are not masked out. Additionally, any single grid box that meets this criterion, but is not immediately adjacent to at least one other box that passes the test, is also masked out. Thus, the colored regions of Fig. 6 denote areas larger than one grid box where soil moisture controls evaporation, the precipitation regime encourages anomalies to persist, and the circulation is conducive to reinforcing moisture anomalies through recycling.

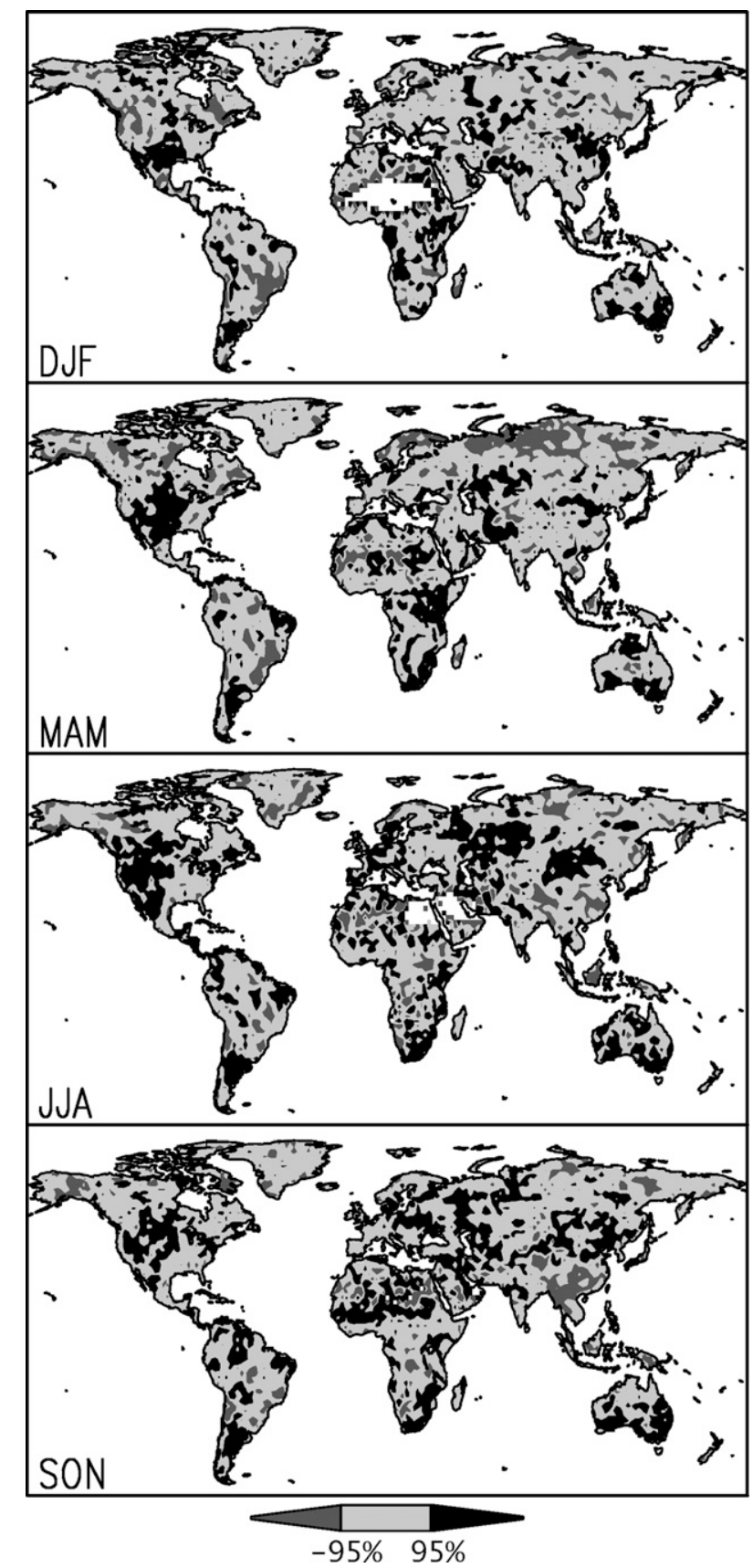

FIG. 5. Same as Fig. 3, but for GOLD-2 monthly soil moisture and recycling ratio.

The presence of all three factors cannot improve climate forecasting if the inherent soil moisture memory time scale is very short, that is, within the range of deterministic prediction. Purple shading in Fig. 6 shows regions where the mean memory is less than 10 days. Encouragingly, there are few large areas and seasons where memory may be too short to be useful: Zimbabwe and the Transvaal during austral summer, Man- 


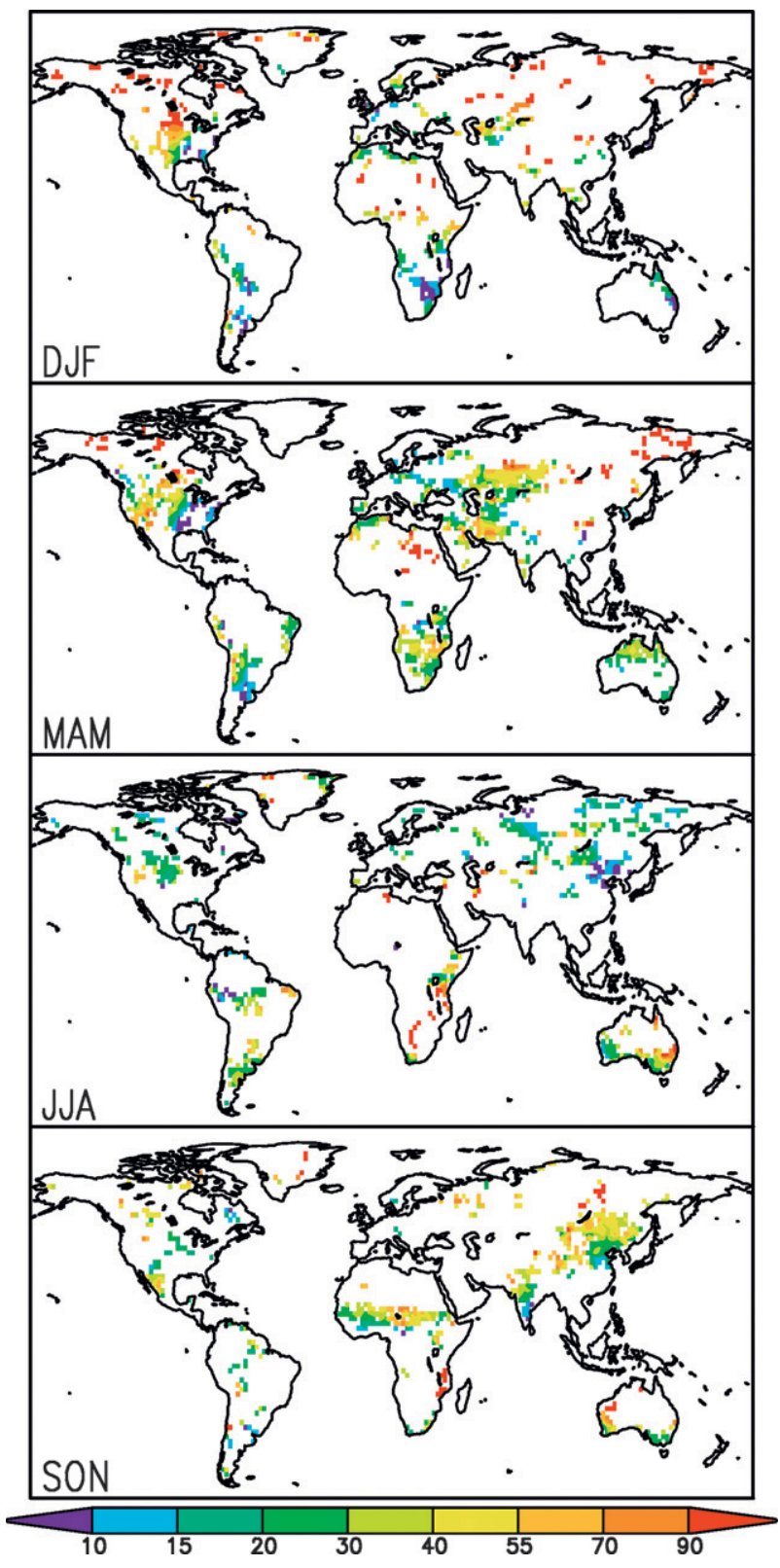

FIG. 6. Soil moisture memory (days). Only regions with positive correlations among all terms shown in Figs. 3-5 are shaded.

churia in boreal summer, and the Pampas and the lower Mississippi River basin during MAM.

Most of the major contiguous regions and seasons identified in Fig. 6 are monsoon locations during the dry-down phase after the end of the wet season. These include the summer monsoon regions of North America, the Sahel, most of the Indian subcontinent, Inner Mongolia, and Manchuria during boreal autumn, and Northern Australia, southern Africa, the Pampas, Gran Chaco, and Nordeste during austral autumn. The Mato Grosso shows up somewhat later, during austral winter. Winter monsoon areas are highlighted as well. Southern and western Australia are shaded during austral winter and spring, North Africa is identified during boreal winter, and much of the Mediterranean, Middle East, southwestern Asia, and western North America are identified during boreal spring. East Africa, which experiences a semiannual cycle of wet and dry seasons, is shaded during both DJF and JJA. In most of these regions, the time after the rainy season is the key agricultural period of the year. The potential for increased predictability at this time of year is especially promising.

The Great Plains of North America are unique. In winter, a broad region in Fig. 6 extends northward from the Gulf of Mexico into southern Manitoba. The region extends from south to north where the memory is beyond three months because the ground is frozen. This area remains largely intact through spring and contracts northward in summer. No other area shows this degree of persistence through three seasons, suggesting that the Great Plains region is uniquely vigorous in its landatmosphere interactions.

Returning to the original hypothesis, we would interpret a significant correlation between soil moisture memory and recycling ratio as a definitive indicator of regional water cycle feedback. Recall that these two datasets have the greatest independence in terms of data consistency. We find that the patterns of correlation between those two fields are quite consistent with others shown, especially Fig. 4, but the correlations are rarely high enough to be significant. When this seasonal correlation field is applied as an additional mask to Fig. 6 , the resulting maps (not shown) look very similar to Fig. 6, but with nearly all of the small speckles removed and a slight reduction in the extent of most of the major regions discussed above. The diminution appears to be most pronounced for the winter monsoon regions. There is almost no change to the extent of the Great Plains area in any of the seasons.

\section{Conclusions}

We have attempted a synthesis of information to quantify the role of the land in the global water cycle. We have brought together several global datasets, each of which characterizes aspects of the land surface and its interaction with the atmosphere on time scales from days to years. These datasets include land surface model integrations driven by observationally based meteorological analysis as well as estimates of soil moisture memory and the rate of atmospheric moisture recycling calculated from land surface analyses and atmo- 
spheric reanalyses. The result is a set of four seasonal global maps (Fig. 6) that show locations where landatmosphere feedback within the hydrologic cycle appears to occur. These feedbacks may provide an additional source of predictability, through improved initialization of the land surface state in these areas within forecast models. This predictability could be exploited to improve the skill of weather and climate prediction.

Areas shaded in Fig. 6 combine evidence of the following: that soil moisture controls evaporation rates, that the climate regime allows anomalies in soil moisture to persist, and that hydrologic anomalies are reinforced through recycling. Furthermore, the color of the shading denotes the local memory time scale-the average time in days for the lagged autocorrelation of soil moisture from the GSWP-2 multimodel analysis to drop below the $99 \%$ significance level.

The memory itself is an important piece of additional information. Regions in shades of blue or green may gain from dynamical extended-range forecasts (up to 30 days) by careful initialization of those forecasts with data from soil moisture observations in those areas. This is the transitional time scale between classical weather and climate forecasts targeted by The Observing System Research and Predictability Experiment (THORPEX). Regions showing yellow or orange shading have longer time scales of soil moisture memory, between 1 and 3 months. This is in the range of classical seasonal climate prediction where the World Climate Research Programme (1995) spearheads research. Numerical seasonal climate prediction may benefit in these regions from better land surface initialization. In the purple and dark blue shaded regions, landatmosphere feedback processes are too short lived to have an impact on climate time scales (beyond the 1-2week range of deterministic predictability); in these regions and seasons, even the most accurate and timely information on the land surface state may be of little use in prediction.

Unlike other experiments that have established "hot spots" for land-atmosphere interaction (e.g., Koster et al. 2004; Wang et al. 2007), this study does not base its conclusions solely on the behavior of GCMs. Each dataset used is constrained in large part by atmospheric observations. Yet, our results largely corroborate the hot-spot regions identified in the model-only studies. Thus, we believe this study brings observational evidence for the patterns and seasonal evolution of these hot spots, with an element of independence from model biases. It is very difficult to measure signs of landatmosphere interaction directly in the real world. The more different ways we can find evidence of land im- pacts on climate, the stronger the case for exploiting a new path to enhanced predictability.

As consensus grows for the locations of specific hot spots, repercussions arise for observing systems. Routine operational soil moisture measurements could be justified in the hot spot regions. Observations of the land surface state in hot spots could be especially important for data assimilation and forecast initialization. It also could be cost effective, at least for climate prediction applications, to limit or concentrate observing stations in these regions.

Some caveats should be noted for this study. We have shown the results of a 24-yr aggregation focused on a specific set of criteria. The location of these regions of apparently important feedbacks may not be static but could fluctuate with conditions. For instance, a normally humid region experiencing a dry year might fall into the positive feedback regime that contributes to persistence of a drought, yet it would recover quickly given a random wet perturbation (e.g., tropical cyclone landfall). The regions suggested by Fig. 6 need not be immutable; in fact, they may well change in a changing global climate (Seneviratne et al. 2006).

It should also be noted that we have not considered all possible sources of memory in the water cycle. One obvious omission is the memory of past conditions that the state of vegetation might convey from season to season, or year to year. Dynamic vegetation is beginning to be considered as a component of operational prediction models and no reanalysis models include this feature yet. Therefore, we believe that addressing the vegetation impacts with this approach would be somewhat premature, while we recognize that vegetation is an important facet of the problem.

Finally, this method is as strongly constrained by observations as is possible at the global scale with the data available. However, the results remain susceptible to model error, particularly in the soil moisture-ETboundary layer relationships (Dirmeyer et al. 2006b).

The results of this study can serve as a starting point to mapping the spatial and temporal extent of regions of important land-atmosphere feedbacks as they pertain to the water cycle. These regions should be refined with subsequent studies and verified through predictability (e.g., data denial or observation system simulation experiments) and prediction studies with numerical models.

Acknowledgments. This work was supported by NSF Water Cycle Research Awards EAR 02-33320 (Dirmeyer), EAR 02-32616 (Schlosser), and EAR 02-35575 (Brubaker). 


\section{REFERENCES}

Beljaars, A. C., P. Viterbo, M. J. Miller, and A. K. Betts, 1996: The anomalous rainfall over the United States during July 1993: Sensitivity to land surface parameterization and soil moisture anomalies. Mon. Wea. Rev., 124, 362-383.

Brimelow, J. C., and G. W. Reuter, 2005: Transport of atmospheric moisture during three extreme rainfall events over the Mackenzie River basin. J. Hydrometeor., 6, 423-440.

Brubaker, K. L., P. A. Dirmeyer, A. Sudradjat, B. S. Levy, and F. Bernal, 2001: A 36-year climatology of the evaporative sources of warm-season precipitation in the Mississippi River basin. J. Hydrometeor., 2, 537-557.

Dirmeyer, P. A., 2000: Using a global soil wetness dataset to improve seasonal climate simulation. J. Climate, 13, 2900-2922.

_ 2006: The hydrologic feedback pathway for land-atmosphere coupling. J. Hydrometeor., 7, 857-867.

—_, and K. L. Brubaker, 1999: Contrasting evaporative moisture sources during the drought of 1988 and the flood of 1993. J. Geophys. Res., 104, 19 383-19 397.

— treatment of vegetation and soil properties in SSiB. COLA Tech. Rep. 78, 25 pp. [Available from the Center for OceanLand-Atmosphere Studies, 4041 Powder Mill Road, Suite 302, Calverton, MD 20705.]

—_, and K. L. Brubaker, 2007: Characterization of the global hydrologic cycle from a back-trajectory analysis of atmospheric water vapor. J. Hydrometeor., 8, 20-37.

— , F. J. Zeng, A. Ducharne, J. C. Morrill, and R. D. Koster, 2000: The sensitivity of surface fluxes to soil water content in three land surface schemes. J. Hydrometeor., 1, 121-134.

— X. X. Gao, M. Zhao, Z. Guo, T. Oki, and N. Hanasaki, 2006a: The Second Global Soil Wetness Project (GSWP-2): Multimodel analysis and implications for our perception of the land surface. Bull. Amer. Meteor. Soc., 87, 1381-1397.

_ - R. D. Koster, and Z. Guo, 2006b: Do global models properly represent the feedback between land and atmosphere? J. Hydrometeor., 7, 1177-1198.

Douville, H., 2002: Influence of soil moisture on the Asian and African monsoons. Part II: Interannual variability. J. Climate, 15, 701-720.

Fennessy, M. J., and J. Shukla, 1999: Impact of initial soil wetness on seasonal atmospheric prediction. J. Climate, 12, 3167-3180.

Guo, Z., and P. A. Dirmeyer, 2006: Evaluation of the Second Global Soil Wetness Project soil moisture simulations: 1. Intermodel comparison. J. Geophys. Res., 111, D22S02, doi:10.1029/2006JD007233.

,-- Z.-Z. Hu, X. Gao, and M. Zhao, 2006: Evaluation of the Second Global Soil Wetness Project soil moisture simulations: 2. Sensitivity to external meteorological forcing. $J$. Geophys. Res., 111, D22S03, doi:10.1029/2006JD007845.

,-- X. Gao, and M. Zhao, 2007: Improving the quality of simulated soil moisture with a multi-model ensemble approach. Quart. J. Roy. Meteor. Soc., 133, 731-747.

Hornberger et al., 2001: A plan for a new science initiative on the global water cycle. U.S. Global Change Research Program, 118 pp.

Kanamitsu, M., W. Ebisuzaki, J. Woollen, S.-K. Yang, J. J. Hnilo, M. Fiorino, and G. L. Potter, 2002: NCEP-DOE AMIP-II reanalysis (R-2). Bull. Amer. Meteor. Soc., 83, 1631-1648.
Koster, R. D., and M. J. Suarez, 1999: A simple framework for examining the interannual variability of land surface moisture fluxes. J. Climate, 12, 1911-1917.

$\longrightarrow$, and —, 2001: Soil moisture memory in climate models. $J$. Hydrometeor., 2, 558-570.

— moisture and precipitation. Science, 305, 1138-1140.

Lorenz, E. N., 1963: Deterministic nonperiodic flow. J. Atmos. Sci., 20, 130-141.

_ 1969: The predictability of a flow which possesses many scales of motion. Tellus, 21, 289-307.

Reale, O., L. Feudale, and B. Turato, 2001: Evaporative moisture sources during a sequence of floods in the Mediterranean region. Geophys. Res. Lett., 28, 2085-2088.

Rudolf, B., H. Hauschild, W. Reuth, and U. Schneider, 1994: Terrestrial precipitation analysis: Operational method and required density of point measurements. Global Precipitation and Climate Change, M. Desbois and F. Desalmond, Eds., NATO ASI Series I, Vol. 26, Springer-Verlag, 173-186.

Schlosser, C. A., and P. C. D. Milly, 2002: A model-based investigation of soil moisture predictability and associated climate predictability. J. Hydrometeor., 3, 483-501.

Seneviratne, S. I., D. Lüthi, M. Litschi, and C. Schär, 2006: Landatmosphere coupling and climate change in Europe. Nature, 443, 205-209.

Simmons, A. J., and J. K. Gibson, 2000: The ERA-40 project plan. ERA-40 Project Rep. Series 1, 63 pp. [Available online at http://www.ecmwf.int/publications/library/ecpublications/_ pdf/ERA40_PRS_1.pdf.]

Stohl, A., and P. James, 2005: A Lagrangian analysis of the atmospheric branch of the global water cycle. Part II: Moisture transports between earth's ocean basins and river catchments. J. Hydrometeor., 6, 961-984.

Sudradjat, A., K. L. Brubaker, and P. A. Dirmeyer, 2003: Interannual variability of surface evaporative moisture sources of warm-season precipitation in the Mississippi River basin. $J$. Geophys. Res., 108, 8612, doi:10.1029/2002JD003061.

Turato, B., O. Reale, and F. Siccardi, 2004: Water vapor sources of the October 2000 Piedmont flood. J. Hydrometeor., 5, 693 712 .

Wang, G., Y. Kim, and D. Wang, 2007: Quantifying the strength of soil moisture-precipitation coupling and its sensitivity to changes in surface water budget. J. Hydrometeor., 8, 551570.

World Climate Research Programme, 1995: Climate variability and predictability (CLIVAR) science plan. WCRP-89, WMO/TD-690, 157 pp.

Xue, Y., P. J. Sellers, J. L. Kinter, and J. Shukla, 1991: A simplified biosphere model for global climate studies. J. Climate, $\mathbf{4}$ 345-364.

_ F. F. Zeng, and C. A. Schlosser, 1996: SSiB and its sensitivity to soil properties-A case study using HAPEX-Mobilhy data. Global Planet. Change, 13, 183-194.

Zhao, M., and P. Dirmeyer, 2003: Production and analysis of GSWP-2 near-surface meteorology data sets. COLA Tech. Rep. 159, 22 pp. [Available from the Center for Ocean-LandAtmosphere Studies, 4041 Powder Mill Road, Suite 302, Calverton, MD 20705.] 